\title{
Optimisation of conditions of phosphorus release from pharmaceutical waste sludge
}

\section{Ping Zeng $\mathrm{PhD}$}

Professor, Chinese Research Academy of Environmental Sciences, Beijing, China (corresponding author: zengping@craes.org.cn)

Juan Li PhD

Post-doctoral Fellow, Chinese Research Academy of Environmental Sciences, Beijing, China

\section{Jianguang Cheng PhD}

Professor, College of Chemical and Environmental Engineering,

Shandong University of Science and Technology, Qingdao, China

\section{Yonghui Song PhD}

Professor, Chinese Research Academy of Environmental Sciences, Beijing, China (corresponding author: songyh@craes.org.cn) Jian Wei PhD

Associate Professor, Chinese Research Academy of Environmental Sciences, Beijing China

With the short supply of phosphorus $(P)$ resources all over the world, more and more phosphorus-rich excess sludge is produced. In this study, a pharmaceutical surplus activated sludge was subjected to alkali and ultrasonic treatment to promote the release of phosphorus. The optimisation of phosphorus release from pharmaceutical surplus activated sludge by alkali and ultrasonic treatment was investigated. The response surface methodology was adopted to optimise the conditions for phosphorus and organic matter release. A quadratic model was established to describe phosphorus and organic matter release. The variance was analysed by using the Design-Expert software, and the optimum operation conditions were decided on. The results indicated that the quadratic model could well fit the relationship between the release of phosphate phosphorus $\left(\mathrm{PO}_{4}{ }^{3-}-\mathrm{P}\right)$ and chemical oxygen demand (COD) and the influencing factors. The order of influence on the release of phosphate phosphorus and COD was as follows: $\mathrm{pH}>$ total solids > ultrasonic power > time. The maximum release of phosphate phosphorus was $15 \cdot 3 \%$.

\section{Introduction}

Phosphorus $(\mathrm{P})$ is an essential nutrient for living organisms. A large amount of phosphate fertiliser needs to be added to the soil for agricultural development to support the growing population (Reijnders, 2014; Van Vuuren et al., 2010). Phosphate is a nonrenewable resource in the world, since almost all phosphorus used in fertilisers is processed from phosphate rocks (Egle et al., 2016) and phosphate rocks are disappearing quickly. The existing phosphate rocks are estimated to last only 50-100 years (Wang, 2010). Thus, it is necessary and urgent to find new phosphate resources and develop efficient technology for phosphorus recovery.

Sewage sludge is an important secondary phosphorus recovery source (Saktaywin et al., 2005). Most of the phosphate in wastewater is transferred into the sludge during the treatment of wastewater and a large amount of sludge has been produced every year (Dong et al., 2013; Yang et al., 2015). With the improvement of water-treatment technology, the phosphorus content in sludge will become higher and higher. However, the direct agricultural use of sewage sludge as fertiliser has been increasingly restricted due to soil and food safety reasons (Ucaroglu and Talinli, 2012). Compared with landfill or agricultural use, incineration was a much more widely used method for sewage sludge treatment at present (Lundin et al., 2004). Therefore, the recovery of phosphorus from sewage sludge has great significance for the sustainable supply of phosphorus.
The key step for phosphorus recovery from sludge is phosphorus release from sewage sludge. Then, phosphate can be precipitated from the aqueous phase as Struvite or calcium phosphate (Jaffer et al., 2002; Parsons and Smith, 2008). The authors' previous study found that phosphorus could be released from sludge by alkali and ultrasonic treatment. However, compared with sludge from municipal wastewater-treatment plants, less phosphorus can be released from the sludge of a pharmaceutical sewage treatment plant treating phosphorusantibiotic-containing wastewater. The authors hope to find the optimal conditions such as total solids (TS), $\mathrm{pH}$, ultrasonic power and time for phosphorus release from pharmaceutical sludge to increase phosphorus release.

The response surface methodology (RSM) was adopted to optimise the conditions for phosphorus release in this study. RSM consists of a group of mathematical and statistical techniques which are used in the development of an adequate functional relationship between a response of interest and a number of associated conditions variables (Tong and Chen, 2009). In general, such a relationship is unknown but can be approximated by a low-degree polynomial model. RSM can display the relationship by the graph, so that the optimal conditions can be chosen by intuitive observation. RSM has been widely used in many fields such as biometrics (Mead and Pike, 1975), the chemical industry (Hill and Hunter, 1966) and environmental science (Ahmadi et al., 2005; Zhai et al., 2017). 
Table 1. Characteristics of the surplus activated sludge

\begin{tabular}{|lc|} 
Parameter & Average value \\
\hline pH & 7.96 \\
TS: $g / g$ & 0.91 \\
VS: $g / g$ & 0.51 \\
TC: $\mathrm{mg} / \mathrm{g}$ & 299.50 \\
TP: $\mathrm{mg} / \mathrm{g}$ & 9.02 \\
TN: $\mathrm{mg} / \mathrm{g}$ & $22 \cdot 61$ \\
\hline
\end{tabular}

In this study, RSM was applied to optimise the conditions that affect the release of phosphate phosphorus $\left(\mathrm{PO}_{4}{ }^{3-}-\mathrm{P}\right)$ and organic matters from pharmaceutical wastewater.

\section{Materials and methods}

\section{Source of sewage sludge}

The surplus activated sludge was collected from one pharmaceutical wastewater-treatment plant whose influent contained fosfomycin. Fosfomycin is a kind of antibiotic with phosphorus in its structure. The collected condensed sludge was air-dried for $10 \mathrm{~d}$ at ambient temperature, ground in a hammer mill and screened with a $0.45 \mathrm{~mm}$ mesh and then stored at $-20^{\circ} \mathrm{C}$ for later experiments. The characteristics of the surplus activated sludge before treatment are shown in Table 1.

\section{Experimental instruments}

The ultrasonic instrument was composed of a reactor, an ultrasonic producer, a water-recycling cooling system and a magnetic stirrer, as shown in Figure 1. A mixture of sludge and water were put into the $300 \mathrm{ml}$ reactor, and the reactor stayed in a $1000 \mathrm{ml}$ beaker with cooling water. The frequency and the time of ultrasonic-chemical treatment were $20-25 \mathrm{kHz}$ and $30 \mathrm{~min}$, respectively. The ultrasonic-chemical pretreatment was performed with an ultrasonicator (Scientz-IID, Ningbo Xinzhi Ultrasonic

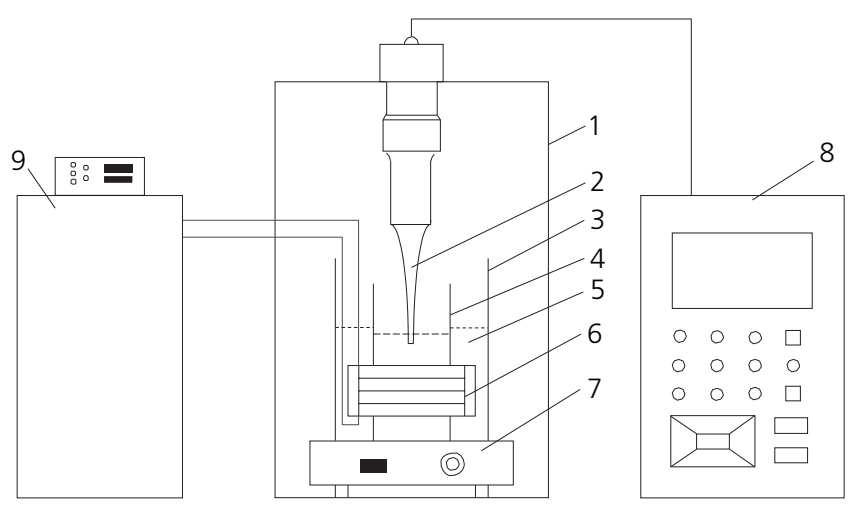

Figure 1. Schematic diagram of ultrasonic treatment device. 1, sound-proof box; 2 , ultrasonic detector; 3 , beaker; 4, beaker;

5 , cooling water; 6 , cooler; 7 , magnetic stirrer; 8 , operator;

9, constant-temperature circulator
Electronic Equipment Company, China). The operation condition was set as follows: intermediate impulse ratio of $1: 1$ and sound energy density of $2 \mathrm{~W} / \mathrm{ml}$. During the pretreatment, the prepared sample was mixed with a magnetic stirrer. The tip diameter of the ultrasonic detector was $6 \mathrm{~mm}$, and the tip was put under a $1 \mathrm{~cm}$ mixed liquor. The temperature was set at $20^{\circ} \mathrm{C}$ by the heater and cooling water-recycling system.

\section{Batch experiment}

The dried sludge was put into the reactor. All the samples were treated in triplicate. Deionised water $(150 \mathrm{ml})$ was added into the first part as blank. Added to the second part was $150 \mathrm{ml}$ deionised water, with the $\mathrm{pH}$ value adjusted using saturation sodium hydroxide $(\mathrm{NaOH})$ solution. The third part was subjected to ultrasonic treatment after the $\mathrm{pH}$ value had been adjusted to the set value. The sludge was left for $20 \mathrm{~h}$ after ultrasonic instrument (intermediate impulse ratio of 1:1). The solid and liquid components were separated by using a centrifuge machine (Thermo Fisher Scientific, USA) for $20 \mathrm{~min}$ at 10000 revolutions/min.

\section{Response surface methodology}

In order to find the optimal conditions for phosphorus and organic matter release as indicated by chemical oxygen demand (COD) release from pharmaceutical waste activated sludge by ultrasonic and alkaline pretreatment, RSM was introduced and designed by the software Design-Expert v8.0 (Stat-Ease Inc., Minneapolis, USA). Based on these experiments, four factors (TS, $\mathrm{pH}$, ultrasonic time, ultrasonic power) were set as independent variables and named $X_{1}-X_{4}$, respectively. Five differently coded levels $(-2,-1,0,+1,+2)$ with TS from $4 \cdot 5$ to $18 \cdot 5 \mathrm{~g}, \mathrm{pH}$ value from 10 to 14 , ultrasonic time from 15 to $75 \mathrm{~min}$, ultrasonic power from 175 to $475 \mathrm{~W}$ were adopted for each factor using Box-Behnken design analysis (Table 2), and the specific experimental arrangement is listed in Table 3. Concentrations of COD and phosphate in solutions were set as responses 1 and 2 . For predicting the optimal point, a function was fitted to correlate the relationship between independent variables and responses.

\section{Analytical methods}

The total carbon (TC) of the sludge was detected by a total organic carbon (TOC)/total nitrogen TN analyser (Multin N/C 2100, Jena, Germany). The supernatant of the sludge was detected by a TOC machine (TOC-L, CPN, CN200, Shimadzu, Japan). Total phosphorus (TP), $\mathrm{pH}$, phosphate phosphorus, $\mathrm{TN}$, total COD and soluble COD were determined according to a standard

Table 2. Codes and levels of RSM design factors

\begin{tabular}{llrrrrr} 
& & \multicolumn{5}{c}{ Value of factors } \\
\cline { 3 - 7 } Factor & Code & -2 & -1 & 0 & 1 & 2 \\
\hline TS: 9 & $X_{1}$ & $4 \cdot 5$ & 8 & $11 \cdot 5$ & 15 & $18 \cdot 5$ \\
pH & $X_{2}$ & 10 & 11 & 12 & 13 & 14 \\
Ultrasonic time: $\min$ & $X_{3}$ & 15 & 30 & 45 & 60 & 75 \\
Ultrasonic power: $W$ & $X_{4}$ & 175 & 250 & 325 & 400 & 475
\end{tabular}


Table 3. The experimental design and results of RSM

\begin{tabular}{|c|c|c|c|c|c|c|}
\hline \multirow{2}{*}{ Series number } & \multicolumn{4}{|c|}{ Value } & \multicolumn{2}{|l|}{ RSM } \\
\hline & $X_{1}$ & $x_{2}$ & $x_{3}$ & $X_{4}$ & Phosphate phosphorus release: $\mu \mathrm{g} / \mathrm{g}$ & COD release: $\mathrm{mg} / \mathrm{g}$ \\
\hline 1 & 0 & -2 & 0 & 0 & $2 \cdot 75$ & 11.41 \\
\hline 2 & -1 & 1 & 1 & 1 & $214 \cdot 36$ & $131 \cdot 80$ \\
\hline 3 & 1 & -1 & 1 & -1 & 4.74 & 37.91 \\
\hline 4 & -1 & -1 & -1 & 1 & $6 \cdot 41$ & $25 \cdot 27$ \\
\hline 5 & -1 & 1 & -1 & -1 & $160 \cdot 66$ & $97 \cdot 85$ \\
\hline 6 & 0 & 0 & 0 & 0 & $32 \cdot 57$ & 51.90 \\
\hline 7 & 0 & 0 & 0 & 0 & $32 \cdot 57$ & 51.90 \\
\hline 8 & 1 & -1 & -1 & -1 & $3 \cdot 37$ & $35 \cdot 15$ \\
\hline 9 & 0 & 2 & 0 & 0 & $3521 \cdot 74$ & $895 \cdot 88$ \\
\hline 10 & 1 & 1 & -1 & 1 & 474.60 & $139 \cdot 11$ \\
\hline 11 & -1 & -1 & 1 & -1 & $7 \cdot 27$ & $23 \cdot 40$ \\
\hline 12 & 2 & 0 & 0 & 0 & $32 \cdot 16$ & $46 \cdot 79$ \\
\hline 13 & -2 & 0 & 0 & 0 & $46 \cdot 69$ & $42 \cdot 98$ \\
\hline 14 & 0 & 0 & 0 & -2 & $24 \cdot 42$ & $42 \cdot 61$ \\
\hline 15 & 1 & 1 & 1 & -1 & $493 \cdot 90$ & $158 \cdot 44$ \\
\hline 16 & 1 & 1 & -1 & -1 & $448 \cdot 74$ & $141 \cdot 54$ \\
\hline 17 & 0 & 0 & 0 & 0 & $32 \cdot 57$ & 51.90 \\
\hline 18 & 1 & -1 & 1 & 1 & $5 \cdot 78$ & $39 \cdot 30$ \\
\hline 19 & -1 & -1 & -1 & -1 & $5 \cdot 35$ & $23 \cdot 04$ \\
\hline 20 & 0 & 0 & -2 & 0 & 14.99 & $35 \cdot 13$ \\
\hline 21 & -1 & 1 & -1 & 1 & $187 \cdot 60$ & $95 \cdot 14$ \\
\hline 22 & 0 & 0 & 0 & 0 & $32 \cdot 57$ & $51 \cdot 90$ \\
\hline 23 & 1 & 1 & 1 & 1 & $516 \cdot 43$ & $185 \cdot 88$ \\
\hline 24 & 0 & 0 & 0 & 0 & 32.57 & $51 \cdot 90$ \\
\hline 25 & 1 & -1 & -1 & 1 & $4 \cdot 35$ & $33 \cdot 38$ \\
\hline 26 & 0 & 0 & 0 & 0 & $32 \cdot 57$ & 51.90 \\
\hline 27 & 0 & 0 & 2 & 0 & $42 \cdot 75$ & $60 \cdot 45$ \\
\hline 28 & -1 & 1 & 1 & -1 & $209 \cdot 34$ & $131 \cdot 23$ \\
\hline 29 & -1 & -1 & 1 & 1 & $7 \cdot 82$ & $14 \cdot 41$ \\
\hline 30 & 0 & 0 & 0 & 2 & $35 \cdot 60$ & $50 \cdot 72$ \\
\hline
\end{tabular}

method (Apha et al., 1998). TS and volatile solids (VS) were determined according to the method of the American Public Health Association (Apha et al., 1998). TS0, VS0 and concentration of phosphorus (CP) 0 referred to the parameters of sludge without pretreatment, while total solid sludge (TSS) and volatile solid sludge (VSS) are the parameters total suspended solids and volatile suspended solids after pretreatment, respectively (Liu et al., 2008). The soluble ratios of TS and VS (STS and SVS, respectively) were then calculated as follows

1. $\mathrm{STS}=(\mathrm{TS} 0-\mathrm{TSS}) / \mathrm{TS} 0 \times 100 \%$

2. $\mathrm{SVS}=(\mathrm{VS} 0-\mathrm{VSS}) / \mathrm{VS} 0 \times 100 \%$

\section{Results}

Model establishment and saliency analysis

The Design-Expert software was used to perform linear fitting of data in tables (Tong and Chen, 2009; Wan et al., 2017), and two polynomial regression equations for phosphate phosphorus release and COD release with TS $\left(X_{1}\right), \mathrm{pH}\left(X_{2}\right)$, ultrasonic time $\left(X_{3}\right)$ and ultrasonic power $\left(X_{4}\right)$ were established, as shown in Equations 3 and 4 . The results are shown in Tables 3 and 4.

$$
\begin{aligned}
Y_{\mathrm{PO}_{4}^{3-} \mathrm{P}} \text { release }= & 32 \cdot 57+46 \cdot 84 X_{1}+404 \cdot 11 X_{2} \\
& +9 \cdot 34 X_{3}+4 \cdot 43 X_{4}+73 \cdot 14 X_{1} X_{2} \\
& +0 \cdot 69 X_{1} X_{3}+1 \cdot 05 X_{1} X_{4} \\
& +9 \cdot 77 X_{2} X_{3}+4 \cdot 80 X_{2} X_{4} \\
& -1 \cdot 61 X_{3} X_{4}-47 \cdot 16 X_{1}^{2} \\
& +383 \cdot 55 X_{2}^{2}-49 \cdot 80 X_{3}^{2}-49 \cdot 01_{4}^{2} \\
3 . \quad & \\
& \\
Y_{\mathrm{COD}} \text { release }= & 51 \cdot 90+9 \cdot 59 X_{1}+109 \cdot 34 X_{2} \\
+ & 7 \cdot 09 X_{3}+1 \cdot 85 X_{4}+6 \cdot 06 X_{1} X_{2} \\
+ & 1 \cdot 18 X_{1} X_{3}+1 \cdot 71 X_{1} X_{4}+8 \cdot 09 X_{2} X_{3} \\
+ & 2 \cdot 26 X_{2} X_{4}+0 \cdot 08 X_{3} X_{4}-12 \cdot 66 X_{1}^{2} \\
+ & 89 \cdot 53 X_{2}^{2}-11 \cdot 93 X_{3}^{2}-12 \cdot 21 X_{4}^{2}
\end{aligned}
$$$$
4 .
$$

A fitted three-dimensional response surface plot was generated by the above statistical model, and the corresponding predicted contour lines of phosphate phosphorus and COD release could be observed in the contour diagrams (Figures 2-7).

Interaction between $\mathrm{pH}$ and TS

The interaction between $\mathrm{pH}$ and TS on the response surface and contour map of phosphate phosphorus and COD release was 
Table 4. Analysis of variance for regression model

\begin{tabular}{|c|c|c|c|c|c|c|c|c|c|c|}
\hline \multirow[b]{2}{*}{$\begin{array}{l}\text { Variation } \\
\text { source }\end{array}$} & \multicolumn{5}{|c|}{ Phosphate phosphorus } & \multicolumn{5}{|c|}{ COD } \\
\hline & Quadratic sum & $\begin{array}{l}\text { Degrees } \\
\text { of } \\
\text { freedom }\end{array}$ & Mean square & $F$ & $P$ & $\begin{array}{l}\text { Quadratic } \\
\text { sum }\end{array}$ & $\begin{array}{l}\text { Degrees } \\
\text { of } \\
\text { freedom }\end{array}$ & $\begin{array}{l}\text { Mean } \\
\text { square }\end{array}$ & $F$ & $P$ \\
\hline Model & 8818600 & 14 & 629900 & $2 \cdot 948836$ & 0.0230 & $5.54 \times 10^{5}$ & 14 & 39592.03 & $3 \cdot 41$ & 0.0122 \\
\hline$X_{1}$ & $52645 \cdot 39$ & 1 & $52645 \cdot 39$ & 0.246456 & 0.6268 & $2205 \cdot 81$ & 1 & $2205 \cdot 81$ & $0 \cdot 19$ & 0.6689 \\
\hline$x_{2}$ & 3919239 & 1 & 3919239 & $18 \cdot 347660$ & 0.0007 & $2.87 \times 10^{5}$ & 1 & $2.87 \times 10^{5}$ & $24 \cdot 75$ & 0.0002 \\
\hline$x_{3}$ & $2092 \cdot 32$ & 1 & $2092 \cdot 32$ & 0.009795 & 0.9225 & $1206 \cdot 95$ & 1 & $1206 \cdot 95$ & $0 \cdot 1$ & 0.7514 \\
\hline$x_{4}$ & 471.0868 & 1 & 471.0868 & 0.002205 & 0.9632 & $81 \cdot 82$ & 1 & 81.82 & $7.06 \times 10^{-3}$ & 0.9342 \\
\hline$x_{1} x_{2}$ & $85601 \cdot 74$ & 1 & $85601 \cdot 74$ & 0.400739 & 0.5362 & $587 \cdot 62$ & 1 & $587 \cdot 62$ & 0.051 & 0.8249 \\
\hline$x_{1} x_{3}$ & 7.573078 & 1 & 7.573078 & $3.55 \times 10^{-5}$ & 0.9953 & $22 \cdot 41$ & 1 & $22 \cdot 41$ & $1.93 \times 10^{-3}$ & 0.9655 \\
\hline$X_{1} X_{4}$ & $17 \cdot 7149$ & 1 & $17 \cdot 7149$ & $8.29 \times 10^{-5}$ & 0.9929 & 46.95 & 1 & 46.95 & $4.05 \times 10^{-3}$ & 0.9501 \\
\hline$x_{2} x_{3}$ & $1526 \cdot 599$ & 1 & $1526 \cdot 599$ & 0.007147 & 0.9337 & $1046 \cdot 8$ & 1 & $1046 \cdot 8$ & 0.09 & 0.7679 \\
\hline$x_{2} X_{4}$ & 368.061 & 1 & 368.061 & 0.001723 & 0.9674 & 81.52 & 1 & 81.52 & $7.03 \times 10^{-3}$ & 0.9343 \\
\hline$x_{3} X_{4}$ & $41 \cdot 31932$ & 1 & $41 \cdot 31932$ & 0.000193 & 0.9891 & $10 \cdot 12$ & 1 & $10 \cdot 12$ & $8.73 \times 10^{-4}$ & 0.9768 \\
\hline$X_{1}^{2}$ & 60991.75 & 1 & 60991.75 & 0.285529 & 0.6009 & 4395.09 & 1 & 4395.09 & 0.38 & 0.5473 \\
\hline$X_{2}^{2}$ & 4035017 & 1 & 4035017 & $18 \cdot 889680$ & 0.0006 & $2.20 \times 10^{5}$ & 1 & $2.20 \times 10^{5}$ & 18.96 & 0.0006 \\
\hline$x_{3}^{2}$ & 68010.93 & 1 & 68010.93 & 0.318389 & 0.5809 & $3904 \cdot 54$ & 1 & 3904.54 & 0.34 & 0.5703 \\
\hline$X_{4}^{2}$ & 67234.46 & 1 & 67234.46 & 0.314754 & 0.5831 & $4090 \cdot 6$ & 1 & $4090 \cdot 6$ & 0.35 & 0.5614 \\
\hline Residue & 3204145 & 15 & $213609 \cdot 7$ & & & $1.74 \times 10^{5}$ & 15 & $11595 \cdot 25$ & & \\
\hline Lack of fit & 3204145 & 10 & $320414 \cdot 5$ & & & $1.74 \times 10^{5}$ & 10 & $17392 \cdot 87$ & & \\
\hline Error & 0 & 5 & 0 & & & 0 & 5 & 0 & & \\
\hline \multirow[t]{2}{*}{ Sum } & $1202 \times 10^{7}$ & 29 & & & & $7 \cdot 3 \times 10^{5}$ & & 29 & & \\
\hline & & & $R=0.8564$ & & & & & $R=0.8725$ & & \\
\hline
\end{tabular}

studied, as shown in Figure 2. The release of phosphate phosphorus increased with the increase in $\mathrm{pH}$ and TS. When the TS used in the experiment ranged from 8 to $15 \mathrm{~g}$, the amount of phosphate phosphorus release at $\mathrm{pH}$ from 11 to 12 was very small. With the increase in $\mathrm{pH}$ from 12 to 13 , the release of phosphate phosphorus increased gradually. When the $\mathrm{pH}$ is between 11 and 13, the amount of phosphate phosphorus released increased with the increase in TS, but the increase was very small. When the TS changed from 13 to $15 \mathrm{~g}$, the amount of phosphate phosphorus released was higher. The effect of $\mathrm{pH}$ and TS interaction on COD release was particularly similar to that of phosphate phosphorus release. However, the perfect interaction between $\mathrm{pH}$ and TS would be reflected by elliptical contours (Muralidhar et al., 2001). In this case, the uncompleted elliptical contours were detected in contour lines of TS and $\mathrm{pH}$, which indicated the independence of the three parameters.

\section{Interaction between TS and ultrasonic time}

Figure 3 shows the effect of interaction between TS and ultrasonic time on the response surface and contour map of phosphate phosphorus and COD release. It is found that the release of phosphate phosphorus increased with the increase in TS. When TS ranged from $10 \cdot 3$ to $15 \mathrm{~g}$, the release of phosphate phosphorus increased with the increase in ultrasonic time, with the highest release of phosphate phosphorus achieved at $48 \mathrm{~min}$. A further increase in ultrasonic time caused the phosphate phosphorus release to decrease slightly, indicating that the ultrasonic time of $48 \mathrm{~min}$ was enough. The release of COD increased with the increase in TS and ultrasonic time in a certain range. It can be seen from the variation trend of the contour lines shown in Figure 3(d) that the elliptical contours represent a perfect interaction between TS and ultrasonic time. Thus, a perfect correlation between TS and ultrasonic time is detected. In addition, the COD release amount was of the maximum value when TS was $12-14 \mathrm{~g}$ and ultrasonic time was $48-54 \mathrm{~min}$.

\section{Interaction between TS and ultrasonic power}

Shown in Figure 4 is the effect of interaction between TS and ultrasonic power on the response surface and contour map of phosphate phosphorus and COD release. It can be seen that the release of phosphate phosphorus increased with the increase in TS. The release phosphate phosphorus initially increased with the increase in ultrasonic power, with the highest released amount of phosphate phosphorus reached at an ultrasonic power of $310-350 \mathrm{~W}$. A further increase in ultrasonic power caused the phosphate phosphorus release to decrease slightly, indicating that the an ultrasonic power of about $325 \mathrm{~W}$ was enough. Similar to the interaction between TS and ultrasonic time, elliptical contours indicated a perfect interaction between TS and ultrasonic power. The effect of TS and ultrasonic power on COD release was particularly similar to that of phosphate phosphorus release. The release of COD and phosphate phosphorus attained the maximum value at TS of $12-14 \mathrm{~g}$ and ultrasonic power of 310-350 W.

\section{Interaction between $\mathrm{pH}$ and ultrasonic time}

The effect of the interaction between $\mathrm{pH}$ and ultrasonic time on phosphate phosphorus release is illustrated in Figure 5. The $\mathrm{pH}$ had a significant effect on phosphate phosphorus release. The 
Journal of Environmental Engineering and Science

Volume 14 Issue JS1
Optimisation of conditions of phosphorus release from pharmaceutical waste

sludge

Zeng, Li, Cheng, Song and Wei

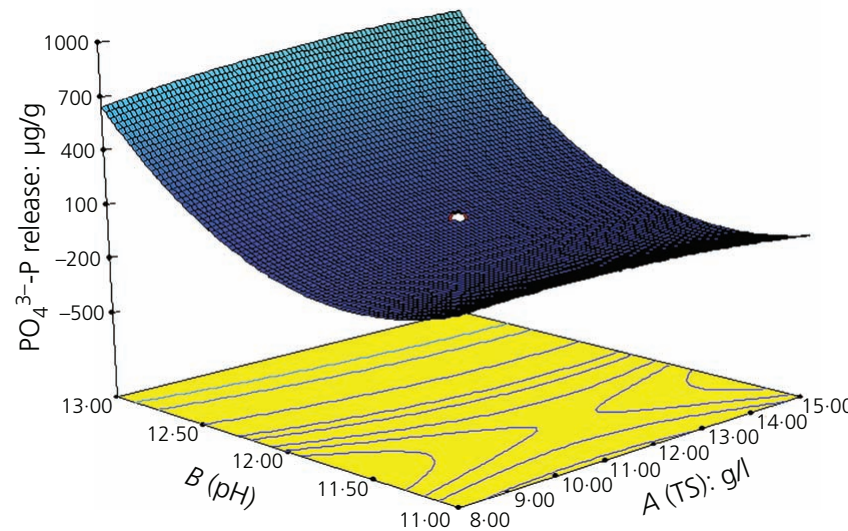

(a)

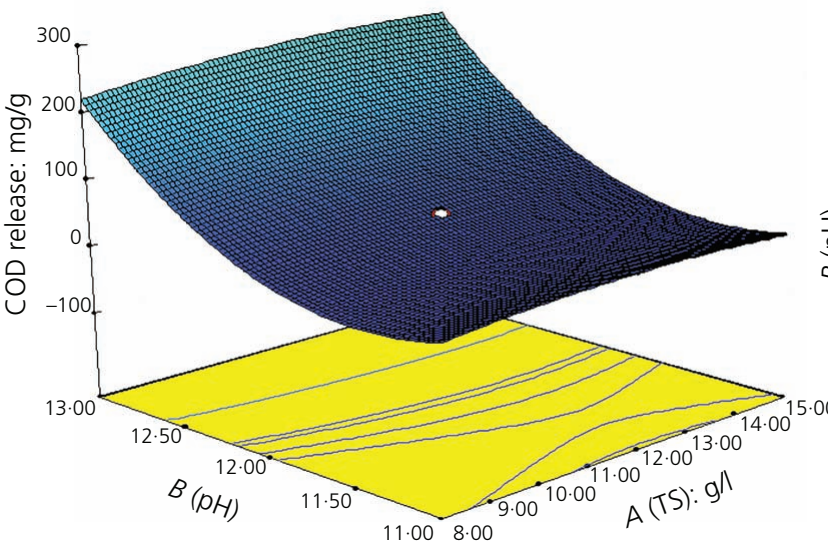

(c)

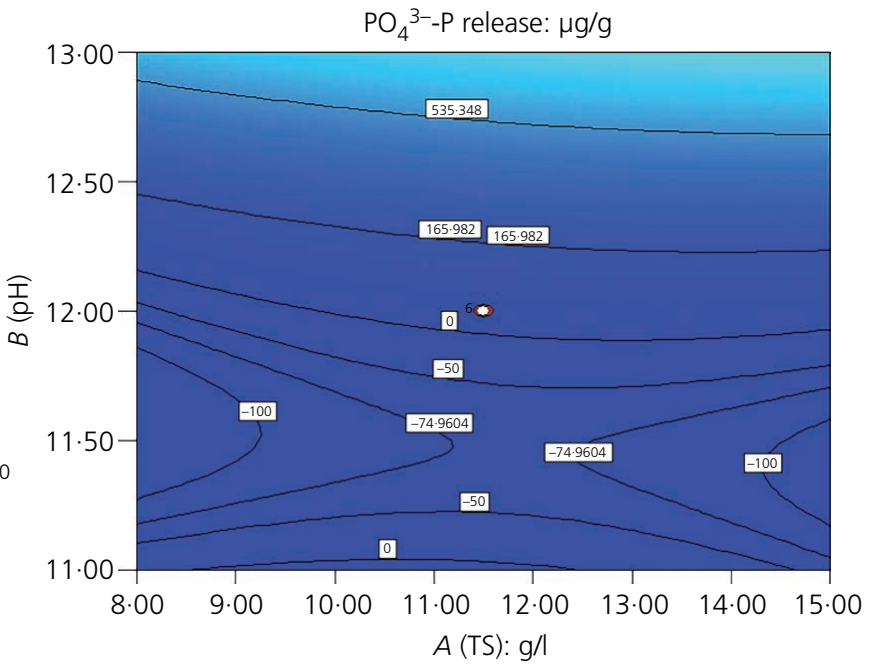

(b)

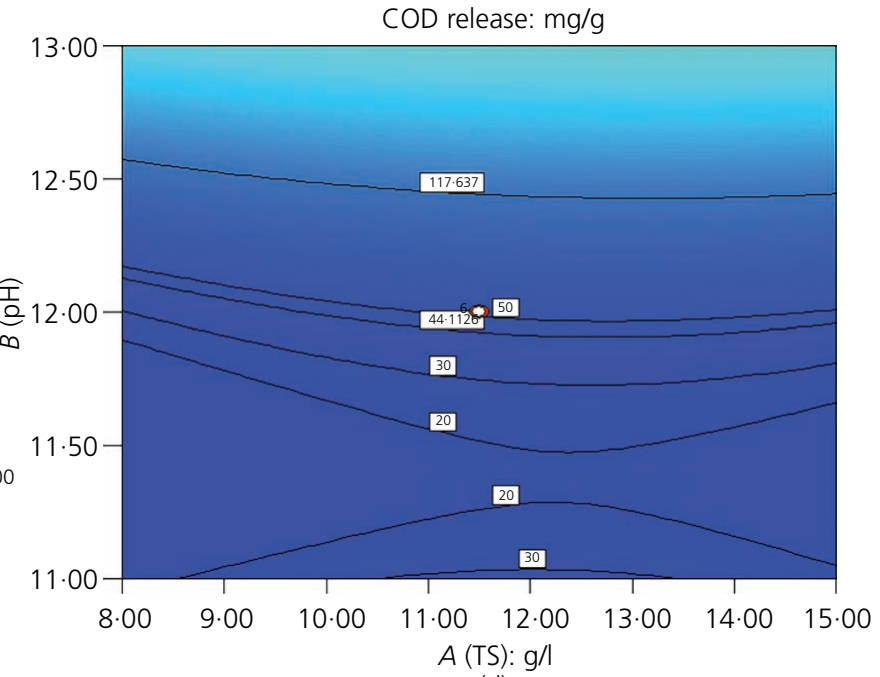

(d)

Figure 2. The effect of interaction between $\mathrm{pH}$ and TS on response surface and contour map of phosphate phosphorus and COD release. (a) The effect of interaction between $\mathrm{pH}$ and TS on phosphate phosphorus release. (b) Contour map of phosphate phosphorus release affected by $\mathrm{pH}$ and TS. (c) The effect of interaction between $\mathrm{pH}$ and TS on COD release. (d) Contour map of COD release affected by $\mathrm{pH}$ and TS

amount of phosphate phosphorus released increased significantly when the $\mathrm{pH}$ was between 11.5 and 13 . In addition, the uncompleted elliptical contours indicated the independence of ultrasonic time and $\mathrm{pH}$. Ultrasonic time did not have much influence on phosphate phosphorus release. The effect of $\mathrm{pH}$ and ultrasonic time on COD release was just particularly similar to that of phosphate phosphorus release.

\section{Interaction between $\mathrm{pH}$ and ultrasonic power}

The effect of interaction between $\mathrm{pH}$ and ultrasonic power on the response surface and contour map of phosphate phosphorus release is shown in Figure 6. It can be seen that $\mathrm{pH}$ had a significant influence on the release of phosphate phosphorus. The release of phosphate phosphorus increased significantly when the
$\mathrm{pH}$ was $11 \cdot 5-13$, while ultrasonic power did not have much influence on phosphate phosphorus release. The effect of $\mathrm{pH}$ and ultrasonic power on COD release was also particularly similar to that of phosphate phosphorus release.

Interaction between ultrasonic time and ultrasonic power The effect of the interaction between ultrasonic time and ultrasonic power on phosphate phosphorus release was also studied. As shown in Figure 7, both ultrasonic time and ultrasonic power do not have much influence on the release of phosphate phosphorus. With the increase in ultrasonic time and ultrasonic power, the release of both phosphate phosphorus and COD increased first and then decreased. The amount of COD and phosphate phosphorus release increased to the maximum value at 


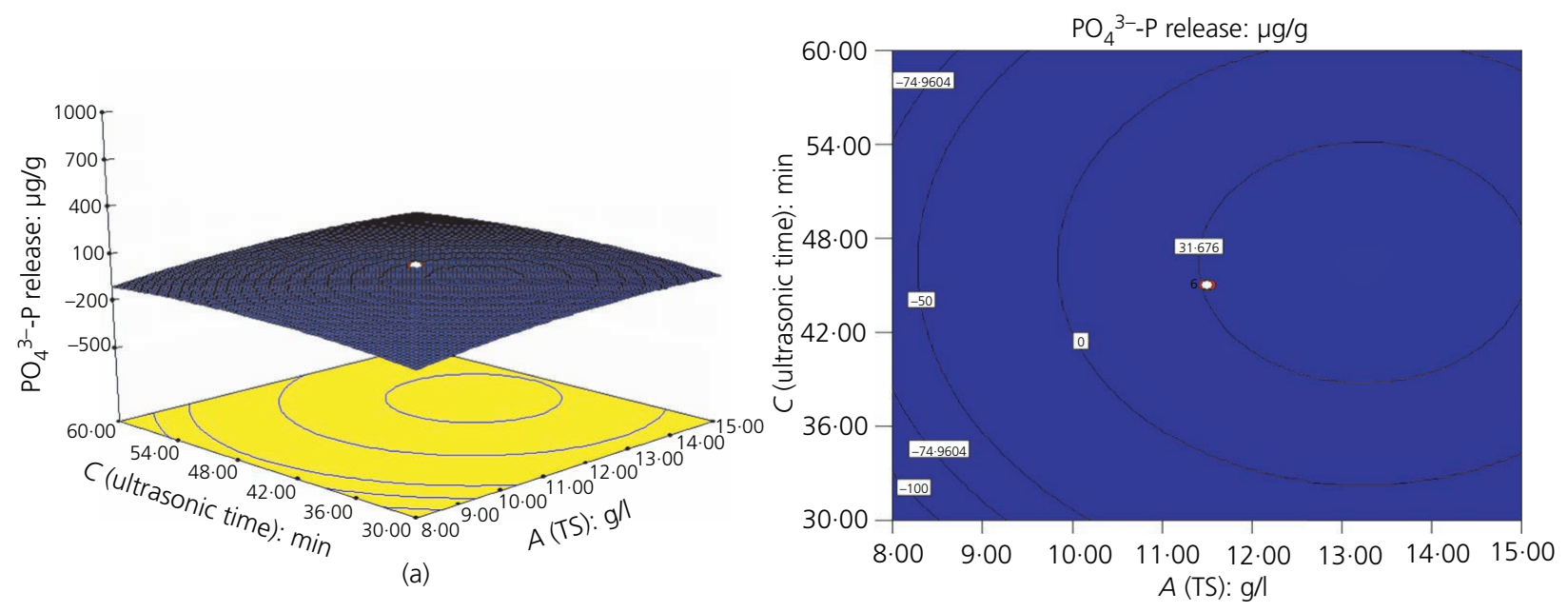

(b)

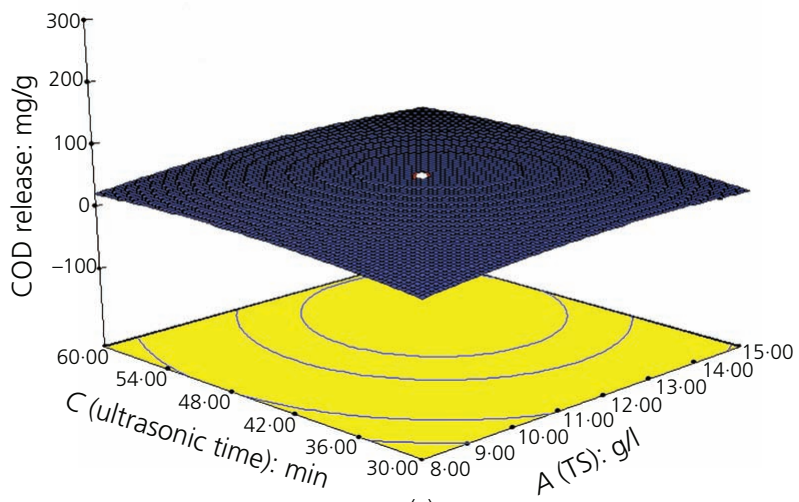

(c)

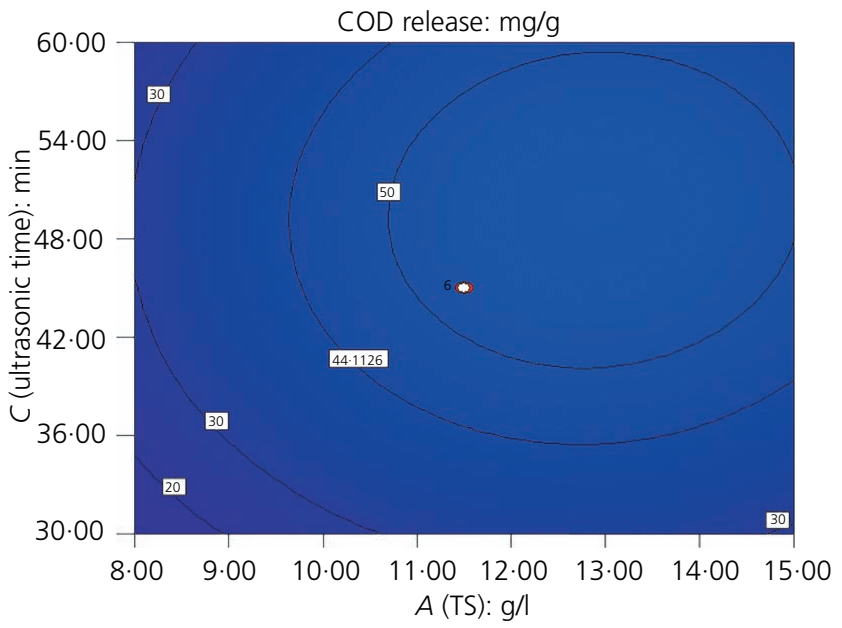

(d)

Figure 3. The effect of interaction between TS and ultrasonic time on response surface and contour map of phosphate phosphorus and COD release. (a) The effect of interaction between ultrasonic time and TS on phosphate phosphorus release. (b) Contour map of phosphate phosphorus release affected by ultrasonic time and TS. (c) The effect of interaction between ultrasonic time and TS on COD release. (d) Contour map of COD release affected by ultrasonic time and TS

an ultrasonic time of $42-50 \mathrm{~min}$ and an ultrasonic power of $310-350 \mathrm{~W}$.

\section{Discussion}

Compared with sludge from a municipal wastewater-treatment plant, less phosphorus can be released from the sludge of a pharmaceutical sewage treatment plant treating phosphorusantibiotic-containing wastewater (Liu et al., 2014). After ultrasonic and alkaline pretreatment, the amounts of phosphate phosphorus released by the two kinds of municipal sludge were 12.60 and $2.24 \mathrm{mg} / \mathrm{g}$, respectively, under the conditions of a $\mathrm{pH}$ of 12 , ultrasonic time of $30 \mathrm{~min}$ and ultrasonic energy of $2 \mathrm{~W} / \mathrm{ml}$. However, the phosphate phosphorus released by the pharmaceutical sludge was $0.05 \mathrm{mg} / \mathrm{g}$. For the pharmaceutical sludge, the amount of phosphate phosphorus released was
$0.05 \mathrm{mg} / \mathrm{g}$, while its TP was $8.92 \mathrm{mg} / \mathrm{g}$. For the Qinhe sludge, one kind of municipal sludge, the amount of phosphate phosphorus released was $12.60 \mathrm{mg} / \mathrm{g}$, while its TP was $13.07 \mathrm{mg} / \mathrm{g}$. It seemed that the operating conditions needed to be improved.

In this study, optimal conditions were determined to improve the release of phosphate phosphorus and organic matter. The RSM model was applied in this study. $P$ is the standard for checking the regression model. When $P<0 \cdot 01$, the regression equation is highly significant. When $0.01<P<0.05$, the regression equation is significant. When $P>0.5$, the regression equation is not significant. As shown in Table 4, the regression model in Equation 3 for phosphate phosphorus release obtained a $P$ of $0 \cdot 01<$ $P<0.05$, indicating that the regression model in Equation 3 was significant. In addition, the regression model in Equation 3 had an 
Journal of Environmental Engineering and Science

Volume 14 Issue JS1
Optimisation of conditions of phosphorus release from pharmaceutical waste

sludge

Zeng, Li, Cheng, Song and Wei

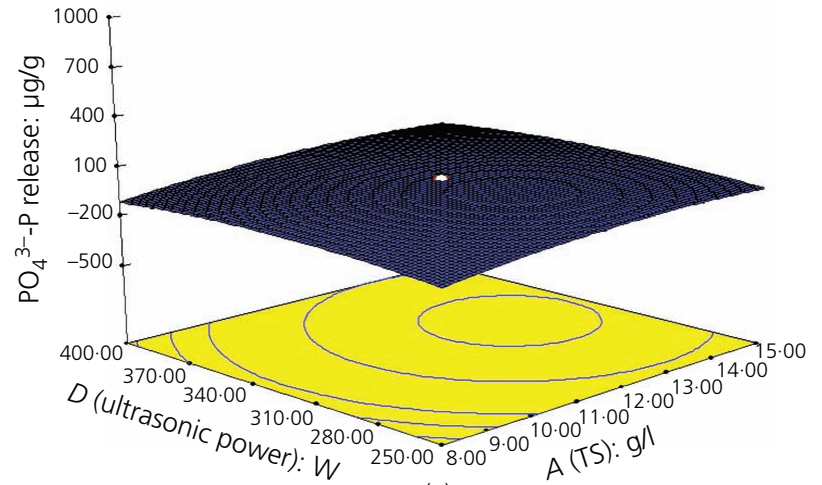

(a)

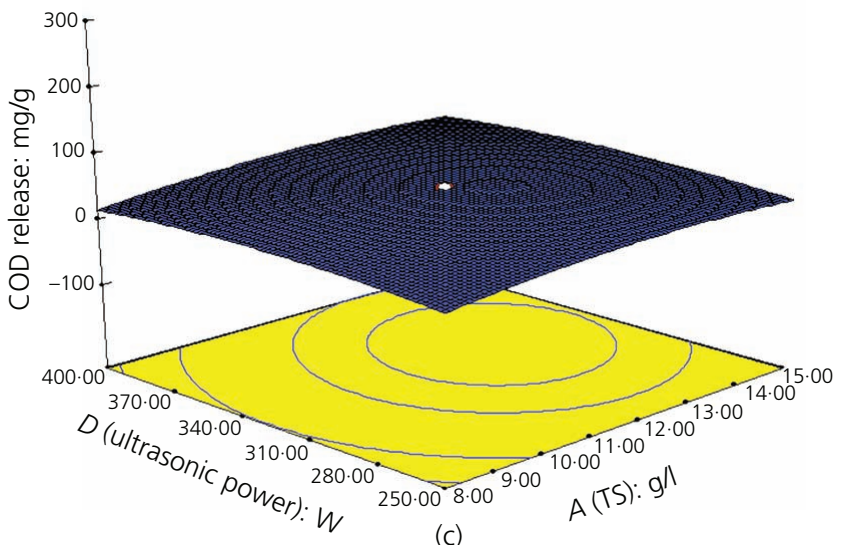

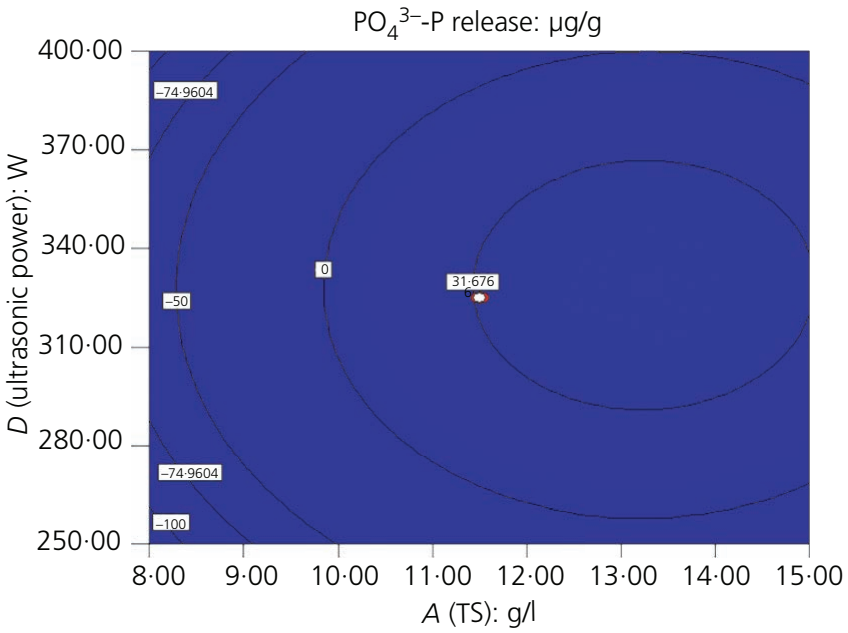

(b)

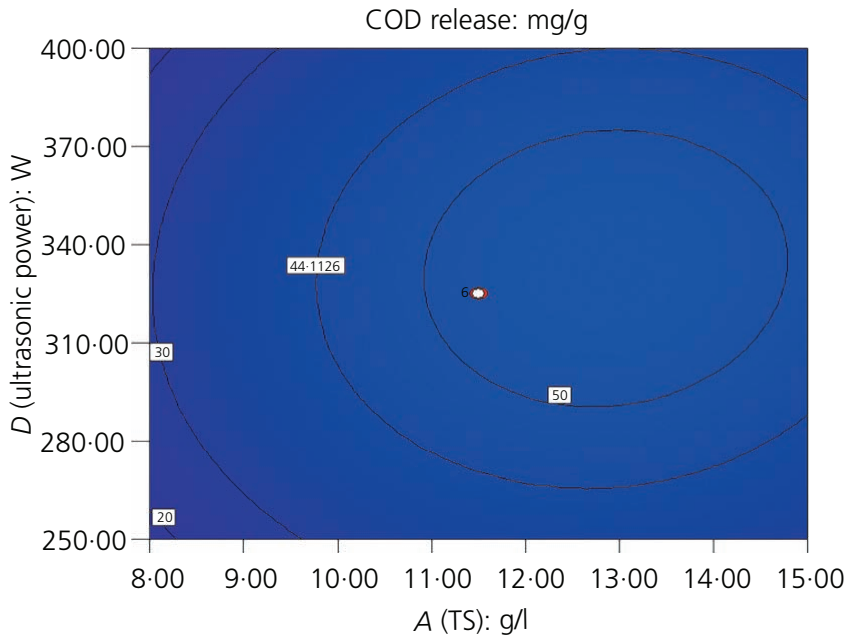

(d)

Figure 4. The effect of interaction between TS and ultrasonic power on response surface and contour map of phosphate phosphorus and COD release. (a) The effect of interaction between ultrasonic power and TS on phosphate phosphorus release. (b) Contour map of phosphate phosphorus release affected by ultrasonic power and TS. (c) The effect of interaction between ultrasonic power and TS on COD release. (d) Contour map of COD release affected by ultrasonic power and TS

$R$ of $0 \cdot 8564$, showing that there was a high correlation between the measured values and the predicted values. Therefore, the regression model in Equation 3 can be used to predict the release of phosphate phosphorus. It can also be seen from Table 4 that TS, ultrasonic time and ultrasonic power had no significant influence on phosphate phosphorus release, but $\mathrm{pH}$ had a significant influence on phosphate phosphorus release. The interactions of the four factors were not significant except for $X_{1} X_{2}$, indicating that the interaction of TS and $\mathrm{pH}$ was the most significant interaction for phosphate phosphorus release.

The value of $F$ suggested the different effects on phosphate phosphorus and COD release: a higher $F$ meant a more significant effect, while a lower $F$ meant a less significant effect. Thus, in this study, the significance of the four factors on phosphate phosphorus and COD release was as follows: $\mathrm{pH}>\mathrm{TS}>$ ultrasonic time $>$ ultrasonic power. $\mathrm{pH}$ had the most obvious effect on phosphate phosphorus and COD release, suggesting that alkaline treatment was the primary factor in detaching phosphate phosphorus and organic matter.

Compared with the phosphate phosphorus release ratio before and after optimisation, the phosphate phosphorus release ratio of pharmaceutical sludge increased from 0.55 to $15 \cdot 3 \%$. It was lower than the phosphate phosphorus release ratio of Qinhe sludge, which was $47 \cdot 7 \%$ (Liu et al., 2014). Considering the influent of the pharmaceutical wastewater-treatment plant, fosfomycin, containing organic phosphorus, was fed to the activated sludge as one component (Qiu et al., 2011). Thus, part of TP came from fosfomycin. The triangular structure of 
Journal of Environmental Engineering and Science

Volume 14 Issue JS1
Optimisation of conditions of phosphorus

release from pharmaceutical waste

sludge

Zeng, Li, Cheng, Song and Wei

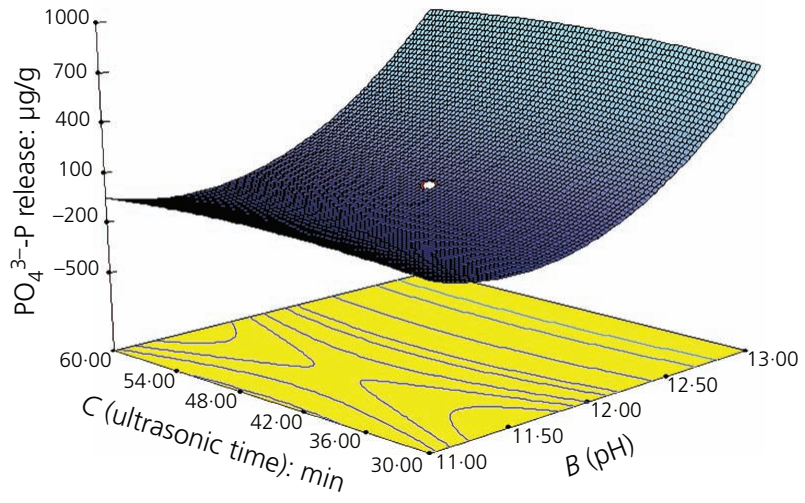

(a)

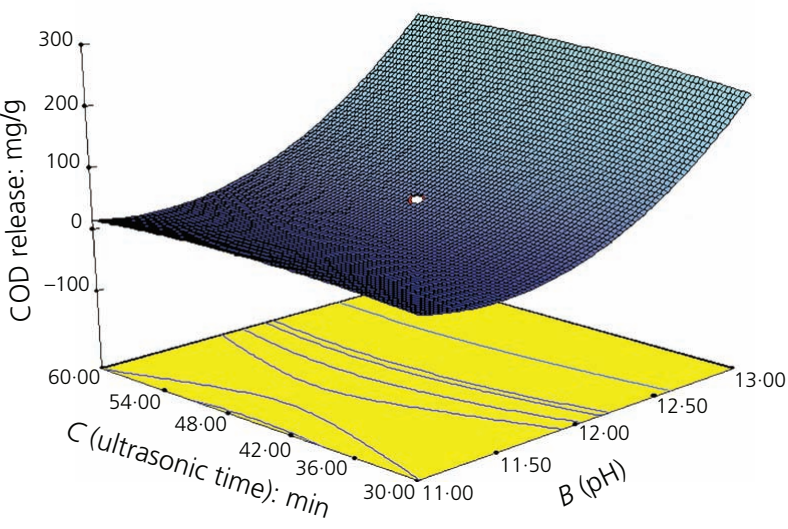

(c)

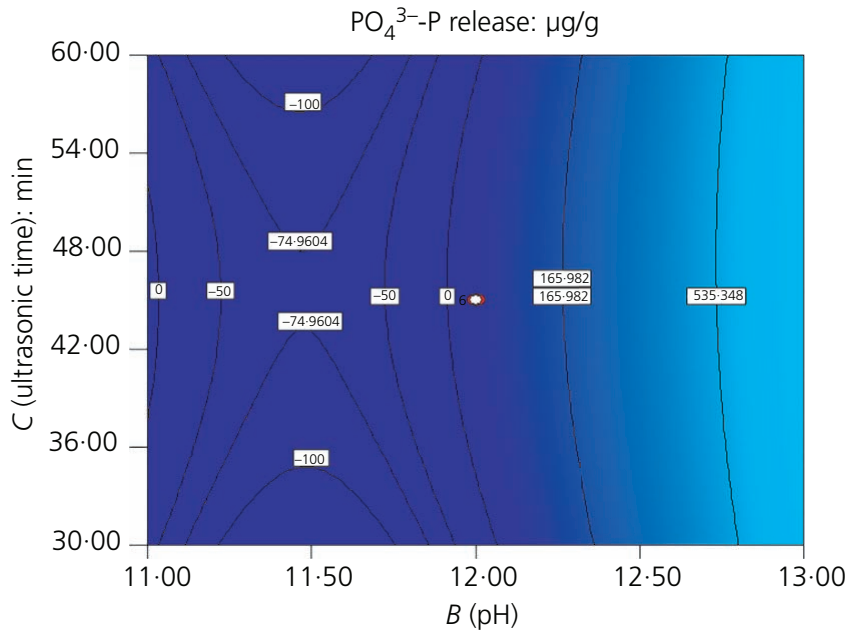

(b)

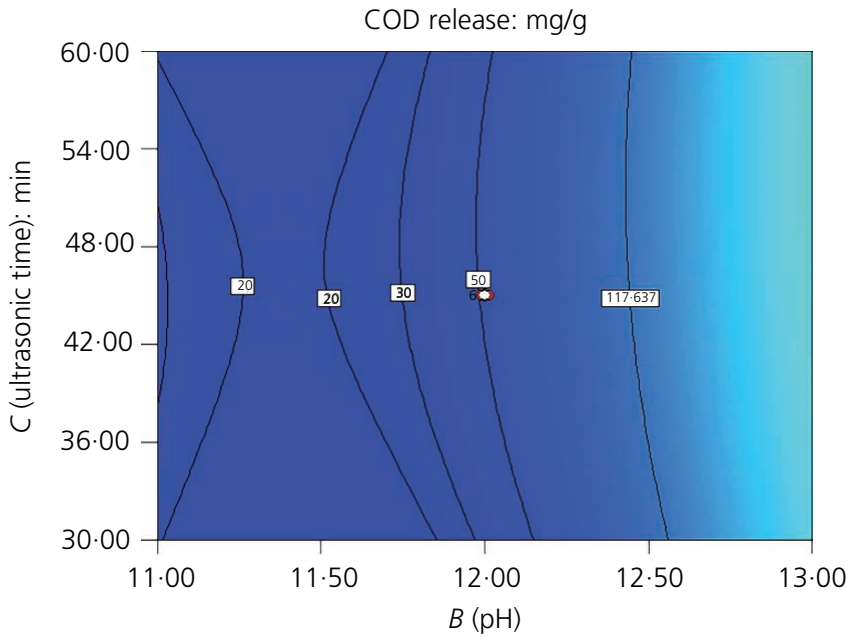

(d)

Figure 5. The effect of interaction between $\mathrm{pH}$ and ultrasonic time on response surface and contour map of phosphate phosphorus and COD release. (a) The effect of interaction between ultrasonic time and $\mathrm{pH}$ on phosphate phosphorus release. (b) Contour map of phosphate phosphorus release affected by ultrasonic time and $\mathrm{pH}$. (c) The effect of interaction between ultrasonic time and $\mathrm{pH}$ on COD release. (d) Contour map of COD release affected by ultrasonic time and $\mathrm{pH}$

fosfomycin possessed high bond energy, which caused the difficulty of breaking the structure and degrading it completely. The low release ratio of phosphate phosphorus by ultrasonic and alkaline treatment indicated that a stronger pretreatment is desired in the future to release phosphate phosphorus from sludge.

\section{Conclusion}

In this study, a quadratic model was applied to simulate the phosphate phosphorus and COD release from pharmaceutical activated sludge treated by alkaline and ultrasonic treatment. The quadratic model could well fit the relationship between the release of phosphate phosphorus and COD and the influencing factors. The effect of $\mathrm{pH}$, TS, ultrasonic power and ultrasonic time on phosphate phosphorus and COD release followed the order $\mathrm{pH}>$ TS $>$ ultrasonic power $>$ ultrasonic time. The maximum release of phosphate phosphorus was $15 \cdot 3 \%$ under the optimal conditions of
$\mathrm{pH}$ of 13 , TS of $15 \mathrm{~g}$, ultrasonic time of $48 \mathrm{~min}$ and ultrasonic power of $332.6 \mathrm{~W}$.

\section{Acknowledgements}

This research was funded by the National Major Scientific and Technological Projects for Water Pollution Control and Management (2017ZX07402003), the Chinese Research Academy of Environmental Sciences Central Public Welfare Scientific Research Project (2016YSKY-027, 2016YSKY-005), the Scientific Research Foundation for the Returned Overseas Chinese Scholars and the Ministry of Education study on phosphorus recovery from surplus activated sludge.

\section{REFERENCES}

Ahmadi M, Vahabzadeh F, Bonakdarpour B, Mofarrah E and

Mehranian M (2005) Application of the central composite design 
Journal of Environmental Engineering and Science

Volume 14 Issue JS1
Optimisation of conditions of phosphorus release from pharmaceutical waste

sludge

Zeng, Li, Cheng, Song and Wei

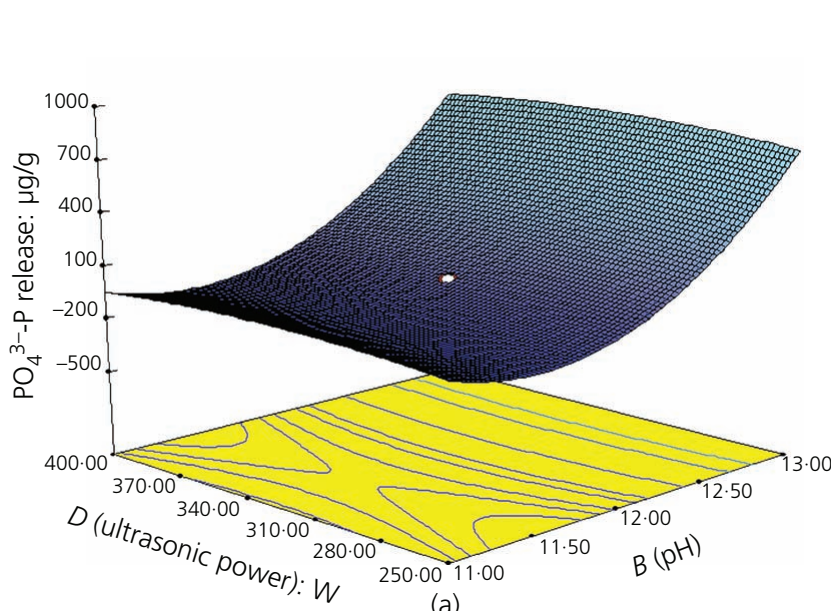

(a)

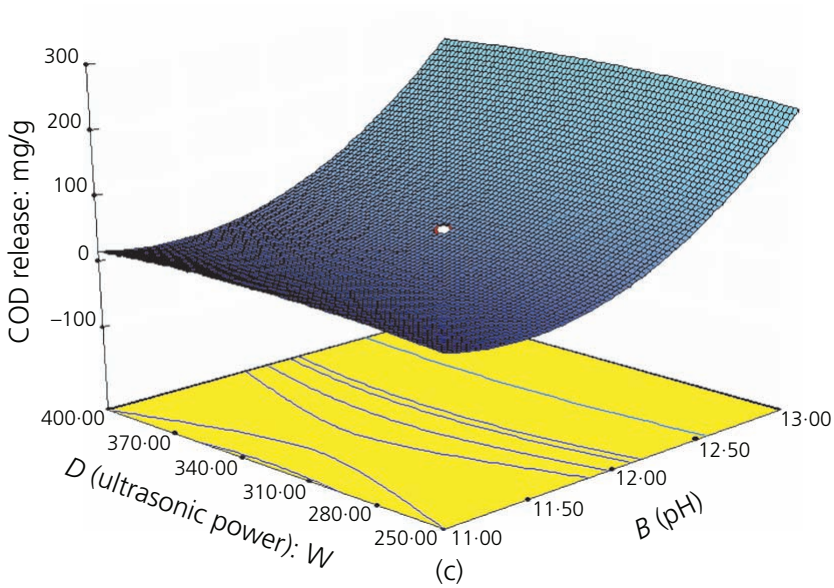

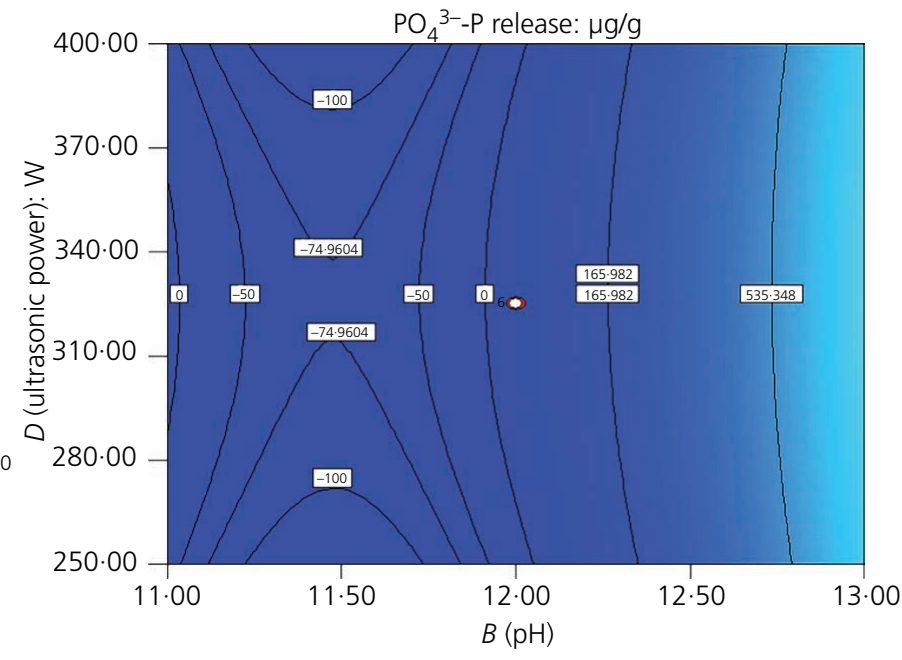

(b)

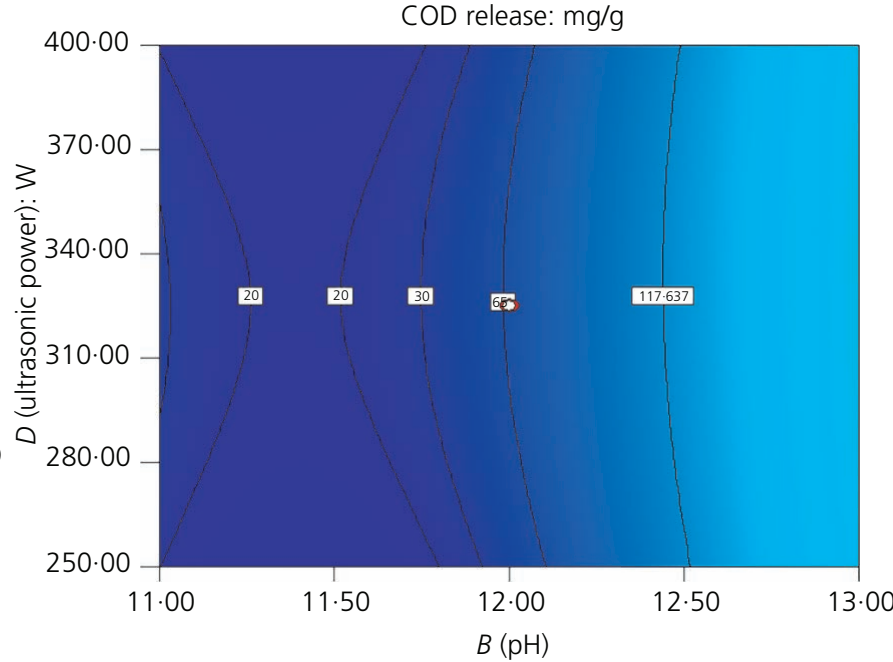

(d)

Figure 6. The effect of interaction between $\mathrm{pH}$ and ultrasonic power on response surface and contour map of phosphate phosphorus and COD release. (a) The effect of interaction between ultrasonic power and $\mathrm{pH}$ on phosphate phosphorus release. (b) Contour map of phosphate phosphorus release affected by ultrasonic power and $\mathrm{pH}$. (c) The effect of interaction between ultrasonic power and pH on COD release. (d) Contour map of COD release affected by ultrasonic power and $\mathrm{pH}$

and response surface methodology to the advanced treatment of olive oil processing wastewater. Journal of Hazardous Materials 123: 187-195, https://doi.org/10.1016/j.jhazmat.2005.03.042.

Apha (American Public Health Association), Awwa (American Water Works Association) and WEF (Water Environment Federation) (1998) Standard Methods for the Examination of Water and Wastewater, 20th edn. Apha, Awwa and WEF, Washington, DC, USA.

Dong B, Liu X, Dai L and Dai X (2013) Changes of heavy metal speciation during high-solid anaerobic digestion of sewage sludge. Bioresource Technology 131: 152-158, https://doi.org/10.1016/j. biortech.2012.12.112.

Egle L, Rechberger H, Krampe J and Zessner M (2016) Phosphorus recovery from municipal wastewater: an integrated comparative technological, environmental and economic assessment of P recovery technologies. Science of the Total Environment 571: 522-542, https:// doi.org/10.1016/j.scitotenv.2016.07.019.
Hill WJ and Hunter WG (1966) a review of response surface methodology: a literature review. Technometrics 8: 571-590, https://doi.org/10.1080/ 00401706.1966 .10490404$.

Jaffer Y, Clark TA, Pearce P and Parsonsa SA (2002) Potential phosphorus recovery by struvite formation. Water Research 36: 1834-1842, https://doi.org/10.1016/S0043-1354(01)00391-8.

Liu XL, Liu H and Chen JH (2008) Enhancement of solubilization and acidification of waste activated sludge by pretreatment. Waste Management 28: 2614-2622, https://doi.org/10.1016/j.wasman.2008. 02.001 .

Liu C, Zeng P, Song YH et al. (2014) Phosphorus releasing from surplus activated sludge by ultrasonic pretreatment. Advanced Materials Research 878: 702-707, https://doi.org/10.4028/www.scientific.net/ AMR.878.702.

Lundin M, Olofsson M, Pettersson GJ and Zetterlund H (2004) Environmental and economic assessment of sewage sludge handling 
Journal of Environmental Engineering and Science

Volume 14 Issue JS1
Optimisation of conditions of phosphorus

release from pharmaceutical waste

sludge

Zeng, Li, Cheng, Song and Wei

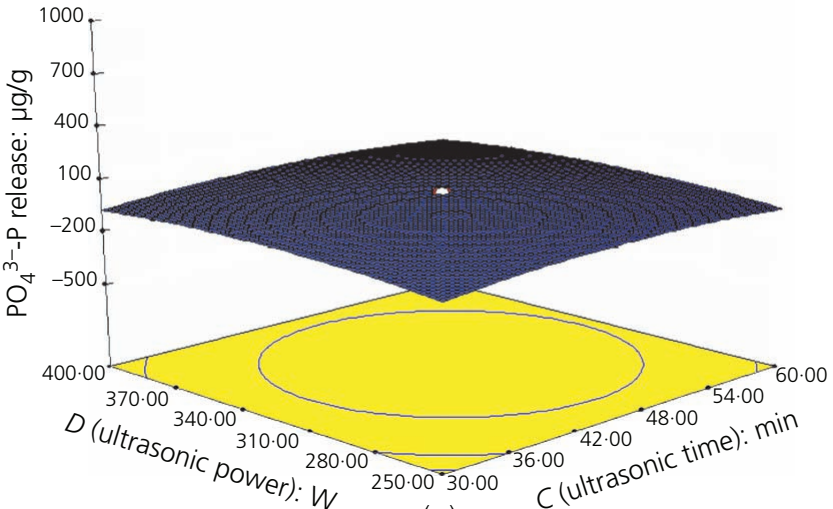

(a)

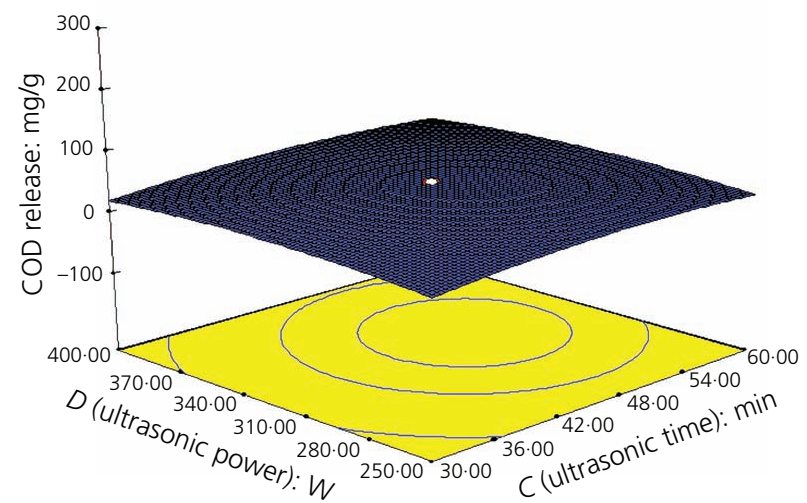

(c)

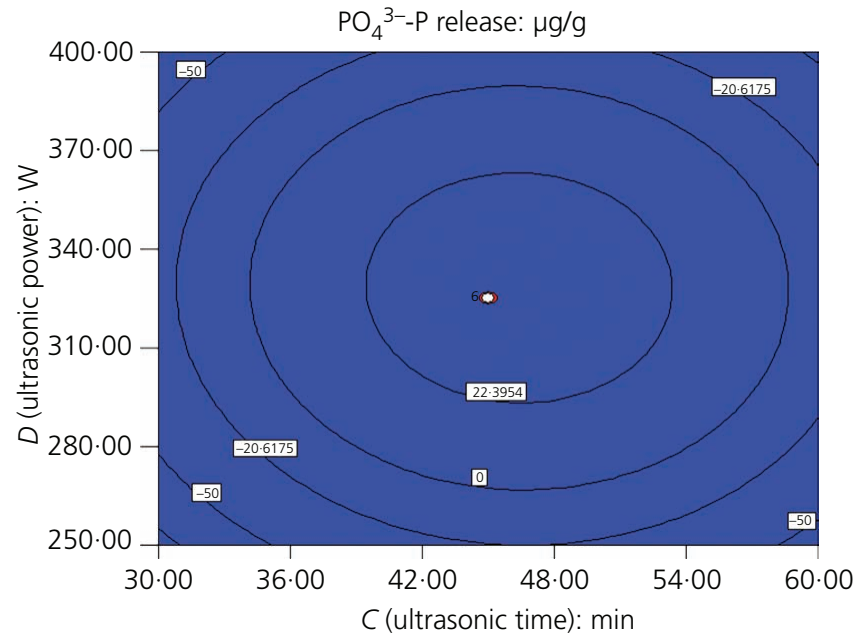

(b)

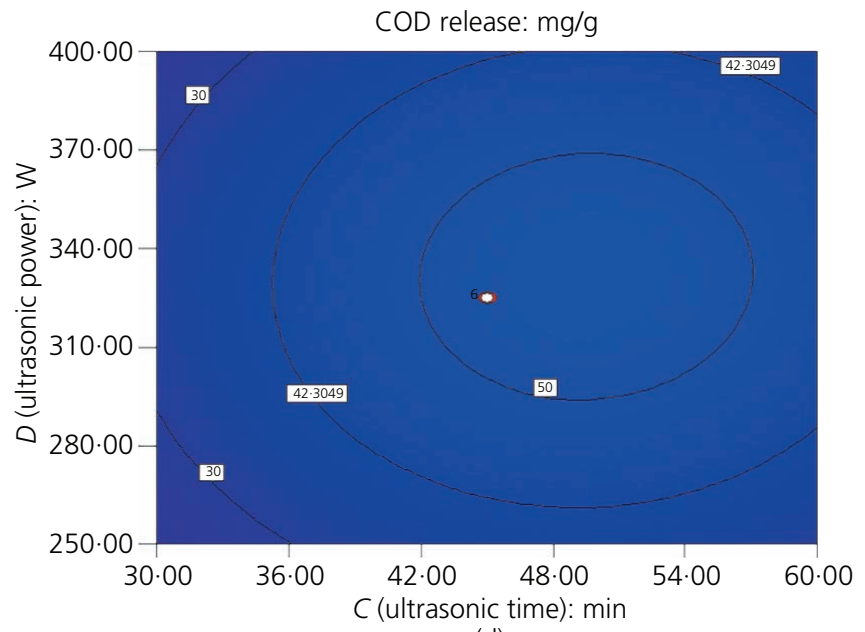

(d)

Figure 7. The effect of interaction between ultrasonic time and ultrasonic power on response surface and contour map of phosphate phosphorus and COD release. (a) The effect of interaction between ultrasonic power and ultrasonic time on phosphate phosphorus release. (b) Contour map of phosphate phosphorus release affected by ultrasonic power and ultrasonic time. (c) The effect of interaction between ultrasonic power and ultrasonic time on COD release. (d) Contour map of COD release affected by ultrasonic power and ultrasonic time

options. Resources, Conservation and Recycling 41(4): 255-278, https://doi.org/10.1016/j.resconrec.2003.10.006.

Mead R and Pike DJ (1975) A review of response surface methodology from a biometrics viewpoint. Biometrics 31(12): 803-851, https://doi. org/10.2307/2529809.

Muralidhar RV, Chirumamila RR, Marchant R and Nigam P (2001) A response surface approach for the comparison of lipase production by Candida cylindracea using two different carbon sources. Biochemical Engineering Journal 9: 17-23, https://doi.org/10.1016/ S1369-703X(01)00117-6.

Parsons SA and Smith JA (2008) Phosphorus removal and recovery from municipal wastewaters. Elements 4: 109-112, https://doi.org/10.2113/ GSELEMENTS.4.2.109

Qiu GL, Song YH, Zeng P, Xiao SH and Duan L (2011) Phosphorus recovery from fosfomycin pharmaceutical wastewater by wet air oxidation and phosphate crystallization. Chemosphere 84: 241-246, https://doi.org/10.1016/j.chemosphere.2011. 04.011 .
Reijnders L (2014) Phosphorus resources, their depletion and conservation, a review. Resources, Conservation and Recycling 93: 32-49, https://doi.org/10.1016/j.resconrec.2014.09.006.

Saktaywin W, Tsuno H, Nagare H, Soyama T and Weerapakkaroon J (2005) Advanced sewage treatment process with excess sludge reduction and phosphorus recovery. Water Research 39: 902-910, https://doi.org/10.1016/j.watres.2004.11.035.

Tong J and Chen YG (2009) Recovery of nitrogen and phosphorus from alkaline fermentation liquid of waste activated sludge and application of the fermentation liquid to promote biological municipal wastewater treatment. Water Research 43: 2969-2976, https://doi.org/10.1016/j. watres.2009.04.015

Ucaroglu S and Talinli I (2012) Recovery and safer disposal of phosphate coating sludge by solidification/stabilization. Journal of Environmental Management 105: 131-137, https://doi.org/10.1016/j.jenvman.2012. 03.029.

Van Vuuren DP, Bouwman AF and Beusen AHW (2010) Phosphorus demand for the 1970-2100 period: a scenario analysis of resource 
Journal of Environmental Engineering

and Science

Volume 14 Issue JS1
Optimisation of conditions of phosphorus

release from pharmaceutical waste

sludge

Zeng, Li, Cheng, Song and Wei depletion. Global Environmental Change 20(3): 428-439, https://doi. org/10.1016/j.gloenvcha.2010.04.004.

Wan CL, Ding S, Zhang C et al. (2017) Simultaneous recovery of nitrogen and phosphorus from sludge fermentation liquid by zeolite adsorption: mechanism and application. Separation and Purification Technology 180: 1-12, https://doi.org/10.1016/j.seppur. 2017.02.031.

Wang XX (2010) Studies of the Cellular Materials Released from Waste Activated Sludge and Phosphorus Recovery during Sludge Reduction
Process. Doctoral thesis, East China University of Science and Technology, Shanghai, China.

Yang G, Zhang G and Wang H (2015) Current state of sludge production, management, treatment and disposal in China. Water Research $\mathbf{7 8}$ 60-73, https://doi.org/10.1016/j.watres.2015.04.002.

Zhai J, Li X, Li W et al. (2017) Optimization of biomass production and nutrients removal by Spirulina platensis from municipal wastewater. Ecological Engineering 108(Part A): 83-92, https://doi.org/10.1016/j. ecoleng.2017.07.023.

\section{How can you contribute?}

To discuss this paper, please submit up to 500 words to the editor at journals@ice.org.uk. Your contribution will be forwarded to the author(s) for a reply and, if considered appropriate by the editorial board, it will be published as a discussion in a future issue of the journal. 